Société d'histoire de la révolution de 1848 et des

révolutions du XIXe siècle

$22 \mid 2001$

Autour de Décembre 1851

Natalie PETITEAU, Napoléon, de la mythologie à l'histoire, Paris, Éditions du Seuil, 1999, 444 p.

\title{
Louis Hincker
}

\section{OpenEdition \\ Journals}

Édition électronique

URL : http://journals.openedition.org/rh19/272

DOI : 10.4000/rh19.272

ISSN : $1777-5329$

Éditeur

La Société de 1848

Édition imprimée

Date de publication : 1 juin 2001

ISSN : 1265-1354

Référence électronique

Louis Hincker, "Natalie PETITEAU, Napoléon, de la mythologie à l'histoire, Paris, Éditions du Seuil, 1999, 444 p. », Revue d'histoire du XIXe siècle [En ligne], 22 | 2001, mis en ligne le 28 juin 2005, consulté le 22 septembre 2020. URL : http://journals.openedition.org/rh19/272 ; DOI : https://doi.org/10.4000/ rh19.272

Ce document a été généré automatiquement le 22 septembre 2020.

Tous droits réservés 


\title{
Natalie PETITEAU, Napoléon, de la mythologie à l'histoire, Paris, Éditions du Seuil, 1999, 444 p.
}

\author{
Louis Hincker
}

1 Il faut souligner l'ambition du livre de Natalie Petiteau qui se donne pour objet d'analyser à la fois la mythologie et l'historiographie napoléonienne et leurs influences réciproques. En quoi l'histoire du Consulat et de l'Empire a-t-elle paru impossible au regard de l'ombre portée par la mythologie sur l'historiographie ? Telle est la question par laquelle débute l'ouvrage qui propose un état très complet des multiples interprétations aussi bien légendaires d'un côté que scientifiques de l'autre. Le livre n'en révèle pas moins les multiples interférences entre les deux registres de discours, et c'est à nos yeux l'un de ses plus grands intérêts. L'historiographie ne s'émancipe pas aisément des enjeux de mémoire, d'autant qu'elle a pu contribuer à les fonder et à les faire perdurer. L'historiographie sur la période n'est que peu à peu sortie depuis une soixantaine d'années du portrait hagiographique, de l'histoire bataille, et du débat des passions contraires. Car faire l'histoire de la mythologie et de l'historiographie napoléoniennes est d'abord, comme l'auteur le souligne, un moyen de dresser un panorama des passions politiques françaises depuis deux cents ans. Le livre inscrit donc la période consulaire et impériale dans le temps long en regardant vers l'aval, en analysant son devenir et son influence. Il s'agit pour Natalie Petiteau de contribuer à un projet historiographique plus vaste en s'interrogeant sur la nature charnière et fondatrice des années 1789-1815. Son ouvrage propose un bilan des renouvellements des études sur la période napoléonienne et son titre peut être lu comme un manifeste.

On sait depuis les travaux de Jean Tulard que dès la période impériale se forgent pour l'avenir les portraits noirs comme roses de l'Empereur, et que sont alors définis les termes des débats passionnés autour de sa personne. Avec Natalie Petiteau, on s'aperçoit de la longévité de cette matrice où chacun, les grands auteurs comme les plus modestes, rivalisent à coup d'anecdotes et d'effets de plume. Enthousiasme et vulgarisation ont dessiné les figures fondatrices du héros prométhéen et de l'ogre 
dévoreur d'hommes. Hagiographie et légende noire n'ont cessé de se répondre, même si la seconde, plus effacée durant la première moitié du XIXe siècle, a surtout resurgit au lendemain du coup d'État du deux décembre 1851. L'une comme l'autre ont influencé pour longtemps l'historiographie, tenue alors de confirmer ou d'infirmer le bien fondé ou la nocivité de l'action des personnalités marquantes, l'empereur en premier lieu, selon un récit chronologique des événements. On peut ici suivre pas à pas et sur le temps long le jeu des louanges et des invectives grâce aux nombreuses citations qui font du livre un recueil de textes précieux en la matière. Le lecteur peut ainsi aisément se rendre compte des débats idéologiques qui ont traversé l'opinion publique. Dans ces conditions, à la veille de la première guerre mondiale, les tentatives d'écrire l'histoire du Premier Empire selon les exigences du projet méthodique de Langlois et de Seignobos ont du mal à s'imposer, car l'histoire napoléonienne demeure longtemps une tribune politique. Natalie Petiteau souligne l'influence des commémorations, de la situation diplomatique et politique tant de la France que de l'Europe, qui expliquent par exemple que le projet scientifique de la Revue des études napoléoniennes lors de sa naissance en 1912, dans le sillage de la Revue historique, n'a $\mathrm{pu}$ résister au retour de l'hagiographique patriotique. C'est encore vrai lors des résurgences de la mythologie impériale en 1921 - au moment du centenaire de la mort de Napoléon - malgré la parution la même année du troisième tome de l'Histoire de la France contemporaine, consacré au Consulat et à l'Empire sous la plume de Georges Pariset, et que l'on peut considérer comme la première synthèse d'une histoire universitaire sur le sujet. Mais c'est précisément à partir de l'entre-deux-guerres que l'histoire et la légende sont de moins en moins confondues, et si le discours officiel durant toute la Troisième République fait de Napoléon le continuateur de la Révolution, on peut relever que l'historiographie universitaire distingue de plus en plus nettement la consolidation des institutions et le non-respect des principes de 1789 afin de souligner la nature autoritaire du régime impérial.

C'est par l'histoire institutionnelle que le renouvellement scientifique des études napoléoniennes a pu tout d'abord s'opérer. C'était un moyen de ne plus s'attacher à la personne de Napoléon pour ainsi se consacrer à l'analyse de l'Empire et à son histoire intérieure. La masse documentaire dans les archives départementales ne pouvait que favoriser ce retour aux sources. La justice, la fiscalité, l'enseignement ont été les domaines les plus explorés. Les historiens y ont trouvé le moyen d'expliquer sans polémiquer. À juste titre, Natalie Petiteau relève que les actes du gouvernement ne font pas la vie de l'Empire et que la question des limites à l'encadrement de la société française par les autorités reste encore quasiment entière tant est particulièrement mal connu l'Empire au village. Le livre ne fait donc pas que dresser un état de l'historiographie la plus récente à propos de la réorganisation administrative, de l'industrialisation, et des mutations agricoles, il comporte aussi un programme de recherche. Pour Natalie Petiteau, une histoire sociale sur le long terme, à la manière de celle qu'elle a pu mener dans sa thèse sur la contribution de la noblesse impériale à la "réinvention nobiliaire" durant le XIXe siècle ${ }^{1}$, peut apporter de nouveaux éclairages sur la pérennité et la portée de l'œuvre napoléonienne. Selon elle, dresser un bilan du Consulat et de l'Empire ne veut pas dire forcément se limiter aux rapports entretenus par Napoléon avec la Révolution. On la suivra d'autant plus en y voyant la possibilité d'étudier des devenirs, sans les confondre dans une comptabilité quelque peu obsessionnelle en terme de "bilan" des "échecs" et des "réussites", pour que l'écriture de l'histoire de la période napoléonienne, et celle de son histoire politique notamment, 
ne soit plus celle du juge. Ajoutons qu'une utile bibliographie thématique permet de s'orienter parmi le très grand nombre d'ouvrages sur le sujet.

\section{NOTES}

1. Nathalie PETITEAU, Élites et mobilités : la noblesse d'Empire au XIXe siècle. 1808-1914, Paris, Éditions de La Boutique de l'histoire, 1997, 714 p. 